\title{
Tillage and Water Content Effects on Surface Soil Hydraulic Properties and Shortwave Albedo
}

\author{
H. P. Cresswell, * D. J. Painter, and K. C. Cameron
}

\begin{abstract}
The modification of surface soil structure affects soil-water processes important in crop production and soil conservation. Effects of pretillage soil water content (PTSW) with multiple-pass tillage operations were determined on soil hydraulic properties and shortwave albedo on freshly tilled soil. Objectives included determination of whether PTSW can be used to improve management of seedbed hydraulic properties and whether tillage-induced soil surface conditions significantly affect albedo. Of the three tillage sequences (minimum, intermediate, and excess tillage) applied to a Templeton silt loam soil (mixed, mesic Udic Ustochrept), the excess tillage sequence resulted in the lowest macropore volume, mainly through a decrease in the volume of aeration pores (pores $>300-\mu \mathrm{m}$ diam.). The slope of the water characteristic between -1.0 and $-1500 \mathrm{kPa}$ matric potential was unaffected by tillage treatments. The excess tillage sequence resulted in a mean hydraulic conductivity (matric potential $=-0.4 \mathrm{kPa}$ ) of $11.1 \mathrm{~cm} \mathrm{~h}^{-1}$, compared with $14.9 \mathrm{~cm} \mathrm{~h}^{-1}$ following minimum tillage. Different PTSW did not cause significant differences in hydraulic properties of freshly tilled soil. The range of tillage-induced soil structures produced did affect shortwave albedo, but to a smaller extent than shown in some previous studies. Bare soil shortwave albedo variation with zenith angle appears soil specific; here a small decrease in albedo was observed as zenith angle increased. In this soil, with commonly practiced tillage sequences and a range of PTSW representative of field conditions, information about PTSW will not help manipulation of hydraulic properties and shortwave albedo in the fresh seedbed.
\end{abstract}

$\mathrm{F}^{\mathrm{n}}$ ELDS sown to cereal crops on the shallow, recent soils of New Zealand's Canterbury plains are often susceptible to wind erosion during the period from tillage until crop establishment. Evaporative water loss during this period may significantly affect the water available for crop growth in this environment. Erodibility is affected by the physical condition of the surface soil and by surface soil water content. Therefore, in assessing tillage practices for this environment, soil-water relations in the resulting seedbed are of importance.

H.P. Cresswell, CSIRO Division of Soils, GPO Box 639, Canberra, ACT 2601, Australia; D.J. Painter, Dep. of Natural Resources Engineering, and K.C. Cameron, Dep. of Soil Science, P.O. Box 84, Lincoln Univ., Canterbury, New Zealand. Contribution from the Dep. of Natural Resources Engineering, Lincoln Univ. Received 2 Mar. 1992. *Corresponding author.

Published in Soil Sci. Soc. Am. J. 57:816-824 (1993).
The soil conditions resulting from tillage influence soil water storage and the loss of soil water through the process of evaporation. The rate of evaporation is determined by either the evaporative capacity of the atmospheric environment or by the supply of water to the evaporating sites, whichever is limiting. Surface soil structure has been shown to affect the proportion of incident radiation absorbed by the soil (Coulson and Reynolds, 1971; Idso et al., 1975; Jackson et al., 1990; Irons et al., 1992). Tillage affects soil hydraulic properties and consequently infiltration and water movement to evaporation sites. Thus, the modification of surface soil structure can influence evaporation by affecting both the available energy supply and water supply for evaporation.

Mechanistic soil water and energy balance simulation models (e.g., Van Bavel and Hillel, 1976) provide useful tools with which to assess changes in the soil water balance resulting from changes in soil hydraulic and physical properties (e.g., Cresswell et al., 1992). To apply models of this type, there is a need to determine the effects of management practices on these soil properties. So, to properly evaluate the suitability of different tillage systems for particular soil and climatic environments, the following must be determined: (i) the soil structure produced by particular tillage systems at various soil water contents, and (ii) the influence of the soil structure produced on soilplant-water processes in a given climate. The former is the emphasis of this study. An earlier study (Cresswell, 1990; Cresswell et al., 1991) considered the effects of tillage management on surface soil physical properties that directly affect the process of sediment transport by wind; in this study we considered tillage effects on properties that influence erosion by affecting soil water relations of the seedbed (i.e., soil hydraulic properties and shortwave albedo).

There is little quantitative information in the literature assessing the effects of multiple-pass tillage operations and PTSW on the soil hydraulic properties important in the description of soil water movement.

\footnotetext{
Abbreviations: PTSW, pretillage soil water content; MAED, mean absolute elevation difference; $L D$, limiting elevation difference; LS, limiting slope index; ANOVA, analysis of variance; ESD, equivalent spherical pore diameter; DNMRT, Duncan's new multiple-range test.
} 
Cresswell et al. (1991) found that multiple-pass tillage operations and PTSW interacted in producing significant effects on the aggregate size distribution of a fresh seedbed. They observed that the avoidance of excessive tillage reduced the likelihood of significant effects of PTSW on aggregate size distribution. This study was to determine if the influence of tillage and water content on soil physical properties observed by Cresswell et al. (1991) translate to large effects on the soil water characteristic and on hydraulic conductivity of freshly tilled soil. This will indicate whether pretillage soil water content in this cropping system can be used in manipulating seedbed hydraulic properties.

We will also consider whether the range of soil surface conditions produced by tillage systems commonly used in New Zealand produce significant variation in shortwave albedo and whether this variation is large in comparison to albedo variation with surface soil water content. Although previous studies (Coulson and Reynolds, 1971; Idso et al., 1975; Jackson et al., 1990; Irons et al., 1992) have shown the dependence of albedo on soil surface roughness, the interaction of surface roughness with surface soil water content has received little attention. Albedo studies have often used surfaces much smoother than those used in commercial cereal cropping operations. We examined the magnitude of surface structure-induced variations in albedo and whether these variations were large enough to warrant albedo being a consideration when deciding on appropriate tillage operations.

\section{MATERIALS AND METHODS}

\section{Experimental Site}

The experimental site was located on the Research Farm, Lincoln University, Canterbury, New Zealand. During the previous $7 \mathrm{yr}$, lucerne (Medicago sativa L.) had been grown in this field. The alluvial soil of the site is classified as Templeton silt loam (Kear et al., 1967; Soil Survey Staff, 1990). The average coarse sand $(0.2-2.0 \mathrm{~mm})$, fine sand $(0.02-0.2 \mathrm{~mm})$, silt $(0.002-0.02 \mathrm{~mm})$ and clay $(<0.002 \mathrm{~mm})$ contents of the experimental site (0-15 cm depth) were $29,20,30$, and $21 \%$, respectively, as determined by particle-size analysis (Gradwell, 1972). The lower plastic limit (lower Atterberg limit) determined for the surface $15 \mathrm{~cm}$ of soil using the method of Thomas (1973) was $0.30 \mathrm{~kg} \mathrm{~kg}^{-1}$ (standard error $=0.004 \mathrm{~kg}$ $\mathrm{kg}^{-1}, 30$ samples). Soil organic matter determined by the losson-ignition technique (Ball, 1964) was 6.2\% (standard error $=0.06 \%, 30$ samples). Dry bulk density and total porosity of the cultivation zone prior to tillage was $1.18 \mathrm{Mg} \mathrm{m}^{-3}$ (standard error $=0.01 \mathrm{Mg} \mathrm{m}^{-3}$ ) and $53.5 \%$ (standard error $=0.32 \%$ ), respectively. Further description of this soil was given by Cresswell et al. (1991).

\section{Experimental Procedure}

The experiment was a split-plot, randomized, complete block design with four replicates. The main plots were three PTSW $\left(0.18,0.23\right.$, and $\left.0.32 \mathrm{~kg} \mathrm{~kg}^{-1}\right)$, which corresponded approximately to $0.58,0.76$ and 1.0 times the lower plastic limit. This water content range is representative of that at which soils are commonly tilled in Canterbury. Each main plot was split into three 3.2 by $14 \mathrm{~m}$ subplots, each of which had a different tillage sequence treatment. The following tillage sequences were used: (i) three heavy spring-tined cultivator passes (minimum tillage); (ii) moldboard plow, then three spring-tined harrow passes (intermediate tillage); (iii) moldboard plow, three rotary cultivator passes, followed by one spring-tined harrow pass (excess tillage). Detailed implement descriptions were given by Cresswell et al. (1991).

The trial area was sprayed with a broad-spectrum herbicide (36\% glyphosate [isopropylamine salt of $\mathrm{N}$-(phosphonomethyl) glycine]) and residual plant material was removed to ground level using a lawn mower prior to tillage. Soil water control was achieved with a sprinkler irrigation system. Christiansen's coefficient for water application uniformity was $95 \%$ in still air (Christiansen, 1942). Water was applied at an average rate of $3.5 \mathrm{~mm} \mathrm{~h}^{-1}$ through small, self-regulating sprinklers in calm conditions. Each main plot was sampled for soil water determination immediately prior to initial tillage. Gravimetric samples of approximately $300 \mathrm{~cm}^{3}$ were taken from 12 randomly selected sites in each main plot at $0-$ to $15-\mathrm{cm}$ depth. Secondary tillage was completed within $1 \mathrm{~h}$ of initial tillage. Plowing depth was kept constant at approximately $15 \mathrm{~cm}$. No soil measurements were made in areas where tractor wheels traveled during tillage operations.

Measurements of surface roughness and soil hydraulic properties were made in freshly tilled soil before any post-tillage rainfall events had occurred and before plots were irrigated prior to albedo determination. These field measurements and sampling for laboratory analysis were completed within $8 \mathrm{~d}$ of tillage. Albedo measurements then commenced and were completed $22 \mathrm{~d}$ later.

\section{Experimental Measurements}

\section{Near-saturation Hydraulic Conductivity}

Hydraulic conductivity at $-0.4 \mathrm{kPa}$ matric potential (subsequently referred to as near-saturation hydraulic conductivity) was determined in the laboratory using intact cores and a tension infiltrometer (Clothier and White, 1981). The infiltrometer uses a hypodermic syringe needle to restrict air entry and thus maintain the supply potential. Intact soil cores (150$\mathrm{mm}$ length by $200-\mathrm{mm}$ i.d.) were taken from four random locations in each subplot at 0 - to $150-\mathrm{mm}$ depth. The soil was moistened, then allowed to drain for $24 \mathrm{~h}$ prior to sampling. A soil stabilizer (polyvinyl alcohol) was applied to the soil surface prior to this prewetting of the sampling sites to avoid alteration of the surface soil during water application. In the laboratory, the cores were saturated by placing them in a few millimeters of deaerated water until they became wet by capillary uplift. The water level was then adjusted to within a few millimeters of the tops of the cores. After $24 \mathrm{~h}$, the cores were removed from the water and placed on a steel-gauze-covered stand. Fine sand (air entry potential $-3 \mathrm{kPa}$ ) was applied to the upper surface of the core as a slurry to facilitate contact between the soil surface and the base of the infiltrometer. Outflow from the infiltrometer was monitored until steady state was reached (usually $<1 \mathrm{~h}$ ) and the flow rate was determined. Hydraulic conductivity was calculated following Clothier and White (1981) and corrected to a water temperature of $20^{\circ} \mathrm{C}$. A single hydraulic conductivity determination was made on each soil core.

\section{The Soil Water Characteristic}

The matric potential-soil water content relationship was determined on four intact cores taken from random positions in each subplot at a depth of $75 \mathrm{~mm}$ (i.e., half-way between the soil surface and the bottom of the layer of tilled soil). Sampling cylinders of $70-\mathrm{mm}$ length by $200-\mathrm{mm}$ diam. were used in those plots subjected to either minimum or intermediate tillage, while 50 -mm-length by $104-\mathrm{mm}$-diam. cylinders were used in the finer tilth excess tillage plots. The inside of each sampling cylinder was smeared with petroleum jelly before use to minimize edge effects. In the laboratory, cores were saturated by placing them in a few millimeters of deaerated water until they 
became wet by capillary uplift. The water level was then adjusted to within a few millimeters of the tops of the cores. After $24 \mathrm{~h}$, the cores were removed and placed on tension tables for determination of water retention at potentials of -1.0 , $-3.0,-5.0$ and $-10.0 \mathrm{kPa}$. Intact subsamples $(15-\mathrm{mm}$ length by $42-\mathrm{mm}$ diam.) from the center of each tension table sample were equilibrated using pressure plate apparatus at potentials of $-33,-100,-300,-500$ and $-1500 \mathrm{kPa}$. Water contents at -33 and $-100 \mathrm{kPa}$ were determined on three samples per subplot. One sample per subplot was used at $-300,-500$ and $-1500 \mathrm{kPa}$, although $-1500 \mathrm{kPa}$ measurements were repeated from two replicates only. Gravimetric water contents were converted to volumetric by multiplication with measured bulk density values. Pore-size distributions were estimated using the capillarity equation (see Marshall and Holmes, 1988, Eq. [2.10]).

\section{Unsaturated Hydraulic Conductivity}

The unsaturated hydraulic conductivity function was determined with the closed-form analytical solution to the predictive hydraulic model of Burdine (1953) proposed by van Genuchten (1980):

$$
\mathrm{K}_{r}(\psi)=\frac{1-(\alpha \psi)^{n-2}\left[1+(\alpha \psi)^{n}\right]^{-m}}{\left[1+(\alpha \psi)^{n}\right]^{2 m}}
$$

where $K_{\mathrm{r}}$ is the relative hydraulic conductivity, $\psi$ is water potential, and $\alpha$ and $n$ are independent parameters that were estimated by fitting the following equation to soil water characteristic data:

$$
\theta=\theta_{\mathrm{r}}+\frac{\left(\theta_{\mathrm{s}}-\theta_{\mathrm{r}}\right)}{\left(1+(\alpha \psi)^{n}\right)^{m}}
$$

$\theta_{\mathrm{r}}$ is residual volumetric water content, $\theta_{\mathrm{s}}$ is water content at saturation. The value of $m$ is given by:

$$
m=1-2 / n \quad(0<m<1 ; n>2)
$$

The measured near-saturation hydraulic conductivity and the water characteristic function were used as input along with the soil water content at saturation (assumed to equal total porosity $\times 0.90$ ). A nonlinear, least squares curve-fitting program (RETC; van Genuchten, 1978) was used to evaluate the unknown empirical coefficients $\alpha$ and $n$ while simultaneously fitting water characteristic and hydraulic conductivity data. The residual water content was assumed to equal $6.0 \%$ following Rawls and Brakensiek (1989).

\section{Total Porosity}

Dry bulk density was determined, using the method of Gradwell (1972), on four samples each of $2640 \mathrm{~cm}^{3}$ taken randomly from each subplot (40-110-mm soil depth). Particle density was measured and total porosity calculated, also using the method of Gradwell (1972).

\section{Shortwave Albedo}

Shortwave albedo was measured using inverted and upright Kipp and Zonen solarimeters (Model CM11, Kipp \& Zonen DELFT BV, Delft, the Netherlands ${ }^{1}$; spectral range 335-2200 $\mathrm{nm}$ ) positioned $0.5 \mathrm{~m}$ above the soil surface. A correction factor to compensate for the shadow cast by the instruments was calculated from view factor theory (Reifsnyder, 1967). The inverted solarimeter was shielded to prevent errors caused

\footnotetext{
${ }^{1}$ Mention of a trade name or product is for the convenience of the reader and does not constitute a recommendation or endorsement by CSIRO or Lincoln University.
}

by the sensing of solar radiation from the horizons; this restricted the viewing area to $5.56 \mathrm{~m}^{2}$. A view factor adjustment was used to compensate for the restriction (Incropera and de Witt, 1985). Output from the solarimeters was collected with an automatic data logging system (Model CR21x, Campbell Scientific, Logan, UT) as hourly averages using a 10-s sampling interval. Shortwave albedo was recorded as the ratio of reflected to incoming solar radiation. Albedo measurements were made in clear sky conditions where possible. Where sufficient cloud was present to reduce total incoming radiation flux to below $600 \mathrm{~W} \mathrm{~m}^{-2}$, the albedo measurements were discarded. This precaution was taken because the visible fraction $(0.4-0.7 \mu \mathrm{m})$ of total solar radiation under cloudy skies tends to be slightly greater than under a cloudless sky in otherwise similar conditions (Monteith and Unsworth, 1990). This could result in depressed reflection measurement.

Albedo was measured from trial Replicate 2 only, on the plots which were tilled at PTSW of 0.18 and $0.32 \mathrm{~kg} \mathrm{~kg}^{-1}$ (i.e., six subplots in total). Each of the tilled subplots were irrigated individually using the low-volume, high-uniformity spray irrigation system detailed above. Approximately $15 \mathrm{~mm}$ of water was applied to each plot prior to commencement of albedo measurement. Although some disturbance of the surface soil with irrigation application is unavoidable, it is min imized by the design of the irrigation system and by the inherent stability of the soil. Plots used for albedo measurement were covered with rain shelters periodically to ensure that they were not affected by irrigation or rainfall except for the single irrigation immediately prior to albedo measurement. Albedo and concurrent surface soil water measurements continued until the soil surface was visibly air dry. Albedo measurements continued from 2 Jan. until 24 Jan. 1988.

\section{Surface Soil Water Content (Concurrent with Shortwave Albedo)}

Surface soil water content was measured gravimetrically on samples of approximately $170 \mathrm{crn}^{3}$. On each sampling occasion concurrent with albedo measurement (hourly), six replicates of water content samples were taken from the 0 - to $20-\mathrm{mm}$ depth.

\section{Surface Soil Roughness (Concurrent with Shortwave Albedo)}

Surface soil roughness was measured with a point gauge microrelief meter, which allowed measurement of surface elevations with a $1.0-\mathrm{mm}$ resolution over a regular $0.5-\mathrm{m}$ grid. The apparatus was leveled above the soil surface before readings were taken at $0.05-\mathrm{m}$ spacings (hence 100 measurements were made over the $0.25-\mathrm{m}^{2}$ area). Two of these measurement sets were completed on each subplot (i.e., $0.5-\mathrm{m}^{2}$ sample area) used for albedo determination. Soil surface roughness was characterized using the semivariance method of Linden and Van Doren (1986), which is a modified spatial variability procedure (MAED). By calculating MAED $(\Delta Z h)$ and plotting against the spacing between elevation sample points (lag spacing, $\Delta \mathrm{Xh}$ ), a consistent shape of function was obtained. This allowed a regression of consistent form to be applied to many sets of elevation data and the regression coefficients were then used to derive two surface roughness parameters. The model used was:

$$
\Delta \mathrm{Zh}=\frac{1}{\frac{1}{\mathrm{LS}(1 / \Delta \mathrm{Xh})}+\frac{1}{\mathrm{LD}}}
$$

The LD parameter is an estimation of the central tendency of the difference in elevation between different points. The LS is 


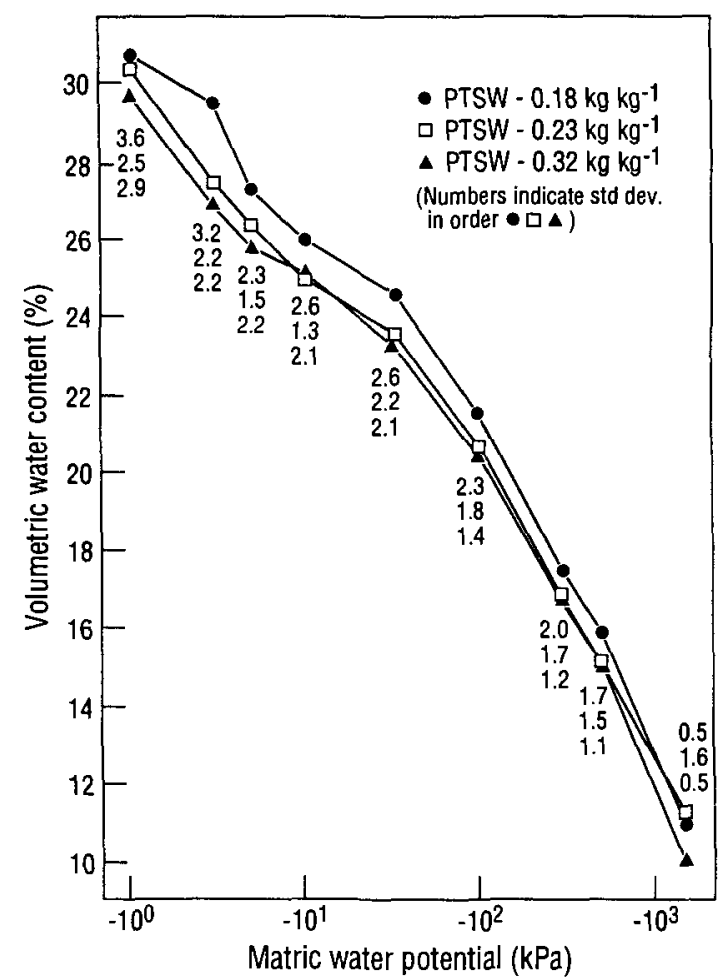

Fig. 1. Effect of pretillage soil water content (PTSW) on the soil water characteristic.

the change in elevation per unit change in horizontal distance between points (Linden and Van Doren, 1986).

The two elevation data sets that were measured on each experimental plot were combined to give 40 transects per plot for the analysis: 20 transects along rows and 20 transects along columns. Spatial dependence was observed, in most cases, at distances $<20 \mathrm{~cm}$ along the $50-\mathrm{cm}$ transects. An equation of the form suggested by Linden and Van Doren (1986) was fitted to the data where lag spacing did not exceed $20 \mathrm{~cm}$.

The LD and LS parameters were calculated on elevation data corrected for slope and toolmark using the procedure of Currence and Lovely (1970). Oriented roughness was removed from the data and a slope correction was made to allow plot comparisons on the basis of random roughness. Previous workers have shown that slope correction is essential if any meaningful comparisons between treatments imposed on the soil are to be made (Currence and Lovely, 1970). The corrected elevations were calculated by

$$
h_{i j}^{\prime}=h_{i j}-\left(h_{. j}-h_{. .}\right)-\left(h_{i .}-h_{. .}\right)-\left(h_{. .}\right)
$$

where $h^{\prime}{ }_{i j}$ is the corrected elevation reading in the $i$ th row and the $j$ th column, $h_{i j}$ is the original elevation reading in the $i$ th row and the $j$ th column, $h_{j}$ is the mean of readings in the $j$ th column, $h_{i .}$ is the mean of readings in the $i$ th row, and $h$. is the overall mean. The upper and lower $10 \%$ of height recordings were retained in the data set, in contrast to the widely adopted method of Allmaras et al. (1966) in which these measurements were discarded.

\section{Aggregate Size Distribution (Concurrent with Albedo)}

Size distribution of soil aggregates was determined using a modified rotary sieve (Lyles et al., 1970). Surface soil samples of approximately $2400 \mathrm{~cm}^{3}$ were obtained from the surface 40 $\mathrm{mm}$ of the soil using a flat-bottomed shovel. Three samples were taken from random positions within each subplot. The air-dried samples were sieved to determine aggregate-size dis-

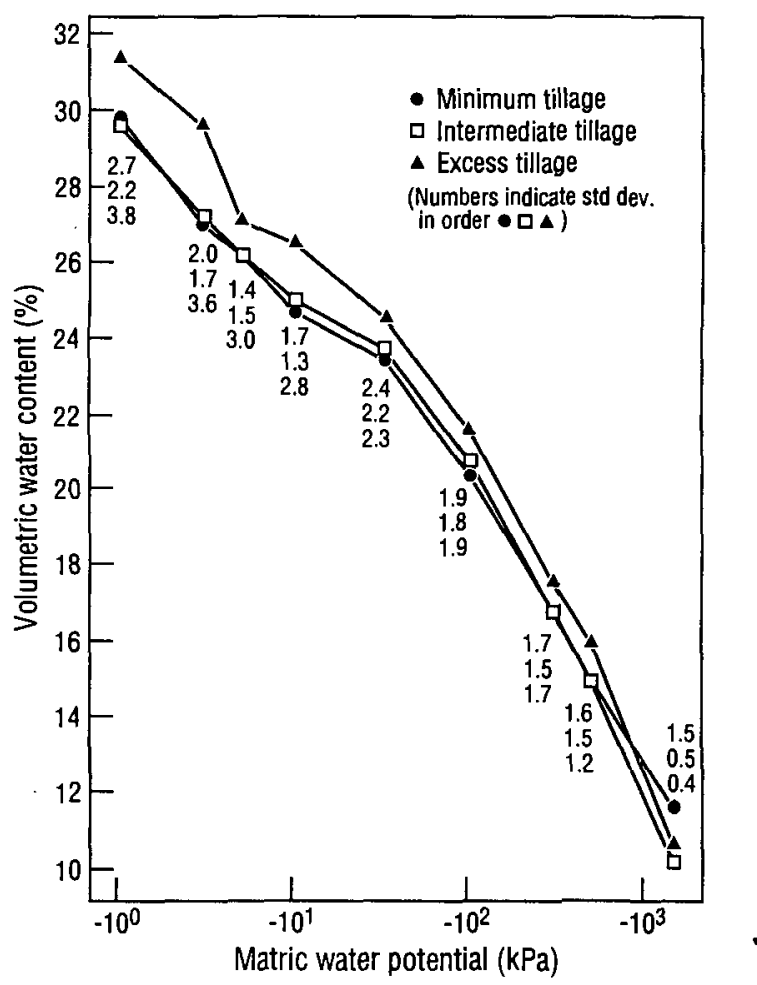

Fig. 2. Effect of tillage sequences on the soil water characteristic.

tribution. The aggregate size ranges determined were: $<0.26-, 0.26$ - to $0.84-,<0.84-, 0.84-$ to $1.47-,<1.47-$, $<4.85-$ , $<18.0-$, and $>18.0-\mathrm{mm}$ diameter. Large pieces of crop residue were removed before sieving.

\section{Statistical Analysis}

The GENSTAT statistical computing package (GENSTAT 5 Committee, 1987) was used for ANOVA. Duncan's new multiple-range test (Steel and Torrie, 1981) was used for individual treatment comparisons; it uses multiple ranges and variable significance levels, depending on the number of means involved, and has the added advantage of simplicity.

\section{RESULTS AND DISCUSSION Total Porosity}

Analysis of variance showed that PTSW had no significant effect on total porosity. Analysis using DNMRT showed that the mean total porosity of the minimum tillage sequence $(67.4 \%)$ was significantly higher $(P<$ $0.05)$ than that of both the intermediate $(62.3 \%)$ and excess tillage $(62.3 \%)$ sequences. There were no significant differences between the intermediate and excess tillage sequences.

\section{Soil Water Characteristic}

The effects of PTSW and tillage sequences on the soil water characteristic are shown in Fig. 1 and 2. Analysis of variance of volumetric water content $\left(\theta_{v}\right)$ at each measured matric potential step in the relation showed that the PTSW treatments had a significant $(P<0.01)$ effect on $\theta_{\mathrm{v}}$ at $-3.0 \mathrm{kPa}$ but not at any of the other measured matric potentials. At each measured potential from -1.0 
Table 1. Mean effect of tillage sequences on macroporosity, aeration porosity, and available water-holding capacity (AWHC) $\uparrow$.

\begin{tabular}{lccc}
\hline $\begin{array}{l}\text { Tillage } \\
\text { treatment }\end{array}$ & Macropores & Aeration pores & AWHC \\
\hline & & $\%$ of total soil volume & \\
\cline { 2 - 3 } Minimum & $42.7 \mathrm{~b} \neq$ & $37.7 \mathrm{a}$ & $13.1 \mathrm{a}$ \\
Intermediate & $37.2 \mathrm{a}$ & $32.6 \mathrm{ab}$ & $14.8 \mathrm{a}$ \\
Excess & $35.7 \mathrm{a}$ & $30.7 \mathrm{~b}$ & $15.9 \mathrm{a}$ \\
\hline
\end{tabular}

† Macropores are pores $>30-\mu \mathrm{m}$ equivalent spherical diameter (ESD), aeration pores are pores $>300-\mu \mathrm{m}$ ESD, AWHC refers to pores between $0.2-$ and $30-\mu \mathrm{m}$ ESD.

$¥$ Means labeled with the same letter are not significantly different at the 0.05 level as determined using Duncan's new multiple-range test.

to $-500.0 \mathrm{kPa}$, PTSW treatments of $0.18 \mathrm{~kg} \mathrm{~kg}^{-1}$ resulted in the largest $\theta_{\mathrm{v}}$ values.

The tillage sequence effects were significant at matric potentials of $-3.0,-10.0,-100.0$ and $-300.0 \mathrm{kPa}$ (ANOVA, $P<0.01$ ). At each measured matric potential $\left(\psi_{\mathrm{m}}\right)$ from -1.0 to $-500.0 \mathrm{kPa}$, the $\theta_{\mathrm{v}}$ in the excess tillage plots was larger than in those of either of the other two tillage sequences. Soil structures produced from widely contrasting tillage systems had little effect on the slope of the section of the water characteristic function in the matric potential range -1.0 to $-1500 \mathrm{kPa}$.

When the nine individual treatments (three tillage sequence treatments and three PTSW treatments) are considered separately, the excess tillage operations at 0.18 $\mathrm{kg} \mathrm{kg}^{-1}$ PTSW produced the largest $\theta_{\mathrm{v}}$ at each measured $\psi_{\mathrm{m}}$.

The effects of PTSW and tillage sequences on the various functional pore size categories (as defined by De Leenheer, 1977) were determined using the measured soil water characteristic functions. Such functional pore size categories are arbitrary and the analysis assumes the validity of the capillary tube model for relating matric potential during a desorption phase to an ESD. The poresize distribution inferred from the water characteristic is therefore an approximation, not a detailed description of pore geometry. Nevertheless, such analysis gives an indication of the pore sizes produced by the various tillage treatments.

Soil macroporosity is defined as the total volume of all pores drained at a matric potential of $-10 \mathrm{kPa}$ (i.e., pores $>30-\mu \mathrm{m}$ ESD). Soil aeration porosity is the volume of pores that drain between 0 and $-1.0 \mathrm{kPa}$ (pores $>300 \mu \mathrm{m} \mathrm{ESD}$ ), and transmission porosity is defined as the volume of pores that drain between -1.0 and -10.0 $\mathrm{kPa}$ matric potential (300-30 $\mu \mathrm{m}$ ESD). The total volume of pores that drain between -10.0 and $-1500 \mathrm{kPa}$ matric potential is defined as available water-holding capacity. Analysis of variance showed tillage sequences had a significant effect on macroporosity $(P<0.01)$. Excess and intermediate tillage sequences resulted in sig. nificantly lower macroporosity (DNMRT, $P<0.05$ ) than minimum tillage (Table 1). Tillage sequences also had a highly significant effect on aeration porosity (ANOVA, $P<0.01)$. Aeration porosity was significantly higher for the minimum tillage sequence (DNMRT, $P<0.05$ ) than for the excess tillage sequence (Table 1). Transmission porosity was not affected significantly by tillage sequences indicating that tillage treatments affect macroporosity mainly by changes in the volume of pores $>300$ $\mu \mathrm{m}$ diam. (aeration pores).
Table 2. Effect of pretillage soil water content (PTSW) of 0.18 , 0.23 , and $0.32 \mathrm{~kg}^{-1}$ and tillage sequences on hydraulic conductivity at $-\mathbf{0 . 4} \mathrm{kPa}$ matric potential (standard error of the mean $=1.01 \mathrm{~cm} \mathrm{~h}^{-1}$.

\begin{tabular}{lccc}
\hline \multirow{2}{*}{$\begin{array}{l}\text { Tillage } \\
\text { treatment }\end{array}$} & \multicolumn{3}{c}{$\begin{array}{c}\text { Hydraulic conductivity at }-0.4 \mathrm{kPa} \\
\text { matric potential }\end{array}$} \\
\cline { 2 - 4 } & $0.18 \mathrm{~kg}^{-1}$ & $0.23 \mathrm{~kg}^{-1}$ & $0.32 \mathrm{~kg}^{-1}$ \\
\hline & & $\mathrm{cm} \mathrm{h}^{-1}$ & \\
Minimum & $15.8 \mathrm{b \dagger}$ & $15.5 \mathrm{~b}$ & $13.2 \mathrm{ab}$ \\
Intermediate & $13.5 \mathrm{ab}$ & $13.6 \mathrm{ab}$ & $13.4 \mathrm{ab}$ \\
Excess & $10.8 \mathrm{a}$ & $10.9 \mathrm{a}$ & $11.7 \mathrm{a}$ \\
\hline
\end{tabular}

† Means labeled with the same letter are not significantly different at the 0.05 level as determined using Duncan's new multiple-range test.

Available water-holding capacity was maximized when the soil was tilled excessively ('Table 1). However, there were no significant differences between the mean available water-holding capacity after the minimum intermediate and excess tillage sequences (DNMRT). Analysis of variance showed PTSW did not significantly affect macro-, aeration, or transmission porosity or available water-holding capacity. Cresswell et al. (1991) discussed the aggregate-size distributions produced in the experiments described here. They observed that the excess tillage sequence resulted in a very fine, pulverized soil with mainly small granular aggregates and that with minimum tillage large aggregates, probably broken along natural planes of weakness, were mixed with a smaller proportion of small aggregates. The large aggregates do not pack as closely, resulting in a greater total porosity consisting mainly of large aeration pores.

\section{Near-Saturation Hydraulic Conductivity}

Tillage sequences had a significant effect on near-saturation hydraulic conductivity (ANOVA, $P<0.01$ ), while PTSW treatments had no significant effect. The mean conductivity (the conductivity for each tillage sequence averaged across all PTSW treatments) after minimum tillage $\left(14.9 \mathrm{~cm} \mathrm{~h}^{-1}\right)$ was significantly higher (DNMRT, $P<0.05)$ than that after excess tillage $\left(11.1 \mathrm{~cm} \mathrm{~h}^{-1}\right)$, while neither were significantly different from intermediate tillage $\left(13.5 \mathrm{~cm} \mathrm{~h}^{-1}\right)$. The individual treatments resulting in the highest conductivity values were minimum tillage at PTSW values of 0.18 and $0.23 \mathrm{~kg} \mathrm{~kg}^{-1}$ (Table 2). These two treatments had significantly higher (DNMRT, $P<0.05$ ) conductivities than each of the excess tillage treatments. There were no other significant differences between treatments. These results confirm that tillage sequence and PTSW treatments that result in a high macropore volume do result in high rates of nearsaturation water flux.

The measurement of the soil water characteristic and near-saturation hydraulic conductivity involved the saturation of soil samples. Structural changes probably occurred during the careful wetting procedure and hence the results reported here are thought to be more representative of a soil that has undergone a field wettingdrying cycle than of a freshly tilled soil. As a field soil settles following wetting and drying cycles, macropore volume might be expected to decrease (Klute, 1982), consequently decreasing near-saturation conductivity. Further work is needed to determine and better under- 


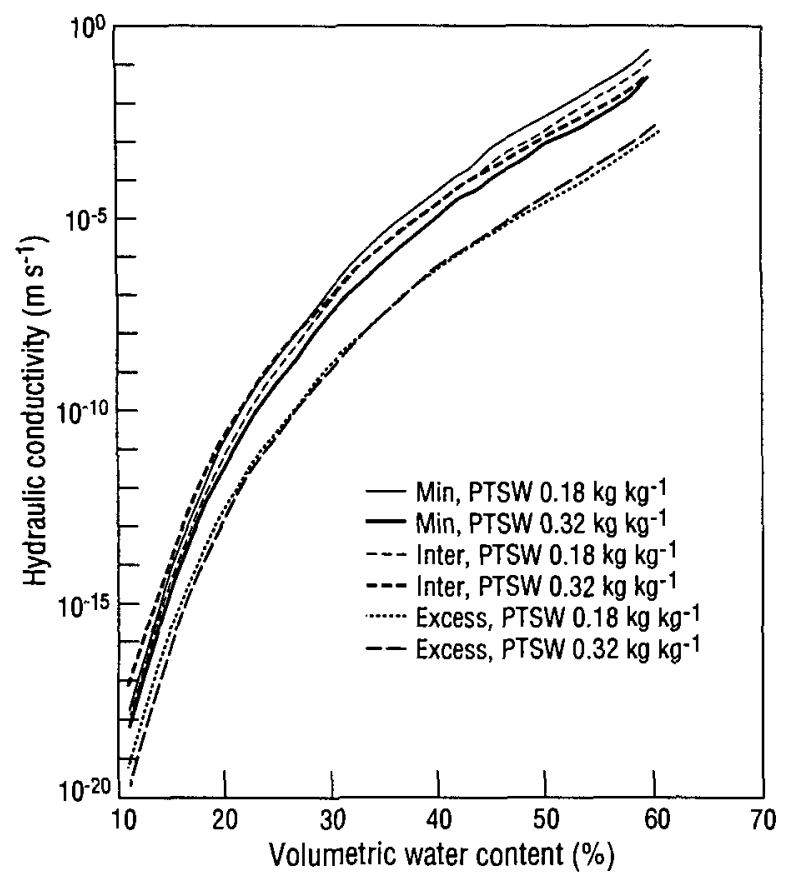

Fig. 3. Effect of pretillage soil water content (PTSW) and minimum (Min), intermediate (Inter), and excess tillage treatments on mean unsaturated hydraulic conductivity (calculated using the method of van Genuchten, 1980).

stand any differences in temporal changes in soil hydraulic properties following different tillage operations.

\section{Unsaturated Hydraulic Conductivity}

The predicted unsaturated hydraulic conductivity function, $K(\theta)$, was affected by tillage sequence, with the smallest conductivities following excess tillage (Fig. 3 ). The minimum and intermediate tillage treatments resulted in similar conductivities on average, both being higher than those following excess tillage. At water contents $>0.20 \mathrm{~m}^{3} \mathrm{~m}^{-3}$, a PTSW effect was apparent in the minimum tillage treatment, with unsaturated hydraulic conductivity following minimum tillage at PTSW 0.18 $\mathrm{kg} \mathrm{kg}^{-1}$ being greater than that following tillage at PTSW of $0.32 \mathrm{~kg} \mathrm{~kg}^{-1}$. Although excess tillage resulted in a greater volume of pores draining between -10 and -1500 $\mathrm{kPa}$ matric potential, compared with the other tillage sequences, this has not resulted in predictions of greater hydraulic conductivity across this range. This might be due to less pore continuity and more tortuosity after excess tillage but is more likely due to the sensitivity of the prediction method to the matching (measured) hydraulic conductivity and the matric potential $(-0.4 \mathrm{kPa})$ at which the measured conductivity was determined.

\section{Bare Soil Shortwave Albedo}

\section{Zenith Angle Effects on Shortwave Albedo}

In order to relate the reflection coefficient of shortwave solar radiation incident on a bare surface directly to soil water content, sun zenith angle effects must first be removed. The effect of zenith angle on shortwave albedo was measured on two widely differing soil tilths, both with air-dry surfaces (water contents of $0.05-0.07$

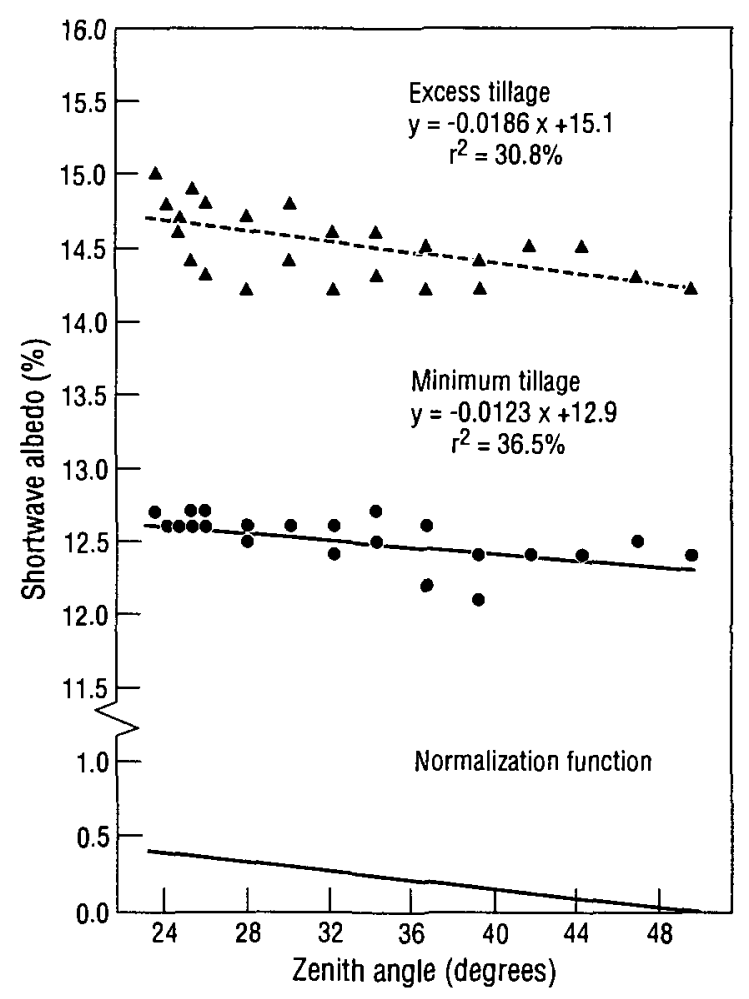

Fig. 4. Effect of zenith angle on bare soil shortwave albedo of two dry soil surfaces (water content $<0.10 \mathrm{~kg} \mathrm{~kg}^{-1}$ ) with difiering structure.

$\mathrm{kg} \mathrm{kg}^{-1}$ ) (Fig. 4). Albedo decreased with increasing zenith angle, although only by a small amount across the range of zenith angles considered $\left(23.5-49.5^{\circ}\right)$. Both regressions differ significantly from zero slope in the negative direction $(P<0.01$, Student's $t$-test). Coulson and Reynolds (1971) also reported decreasing albedo with increasing zenith angle on a disked loam soil with a rough surface condition. However, Coulson and Reynolds (1971) observed increasing albedo with increasing zenith angle on a clay soil. Idso et al. (1975) and Irons et al. (1992) also observed increasing albedo with increasing zenith angle. Comparison of results from this study with those from the work published earlier suggests that the zenith angle effect on reflection appears to be specific to a particular soil and surface condition.

The mechanism of the effect of zenith angle on albedo appears complex and it is not well understood. The angular distribution of radiation incident on the soil surface may affect the relation between albedo and zenith angle. This distribution is influenced both by position of the sun and by atmospheric turbidity (Monteith and Unsworth, 1990). Coulson and Reynolds (1971) suggested that light trapping by multiple reflection within gaps between soil particles would be maximized at small zenith angles where the incident radiation was more normal to the soil surface. For albedo to decrease with increasing zenith angle there must clearly be other mechanisms operating.

The soil surfaces on which the effect of zenith angle has been evaluated in this study and in that of Coulson and Reynolds (1971) (loam soil) appear to be rougher than those used in the studies of Idso et al. (1975) or on the clay also used by Coulson and Reynolds (1971). On 


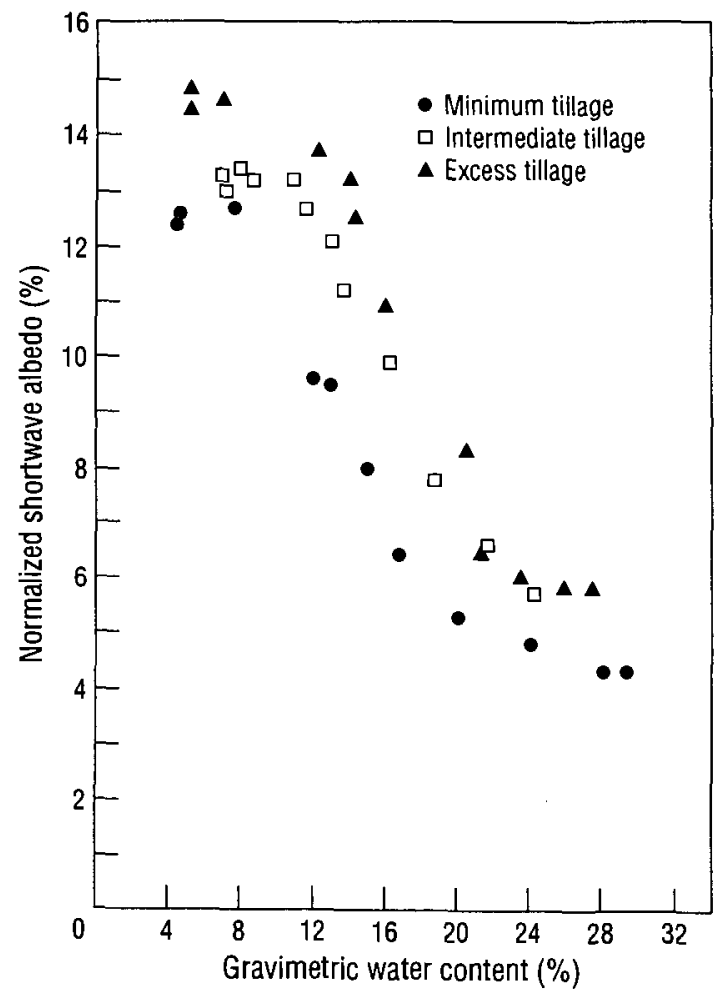

Fig. 5. Effect of soil water content on the normalized bare soil shortwave albedo (all tillage sequences conducted at pretillage soil water content of $0.32 \mathbf{k g ~ k g}^{-1}$ ).

a rough soil surface, irregular surfaces are presented to radiation incident even from high zenith angles. As a consequence, the light trapping mechanism may operate nearly as effectively at high and low zenith angles. With smoother soil, where a more uniform surface is evident, a greater zenith angle effect on light trapping could be expected.

The effects of zenith angle on albedo were determined on dry soils only because the high evaporative demand during the experimental period made the maintenance of a wet surface during clear sky conditions difficult. Idso et al. (1975) observed no differences in zenith angle effect on albedo between wet and dry surfaces. The albedo data were normalized by addition to a zenith angle of $23.5^{\circ}$ using a derived shape function based on the mean of the two curves shown in Fig. 4. The difference between the albedo value at $23.5^{\circ}$ zenith angle on the normalization function, and the albedo value at the zenith angle at which the measurement was taken, was added to the original albedo value.

\section{Soil Water Content, Surface Soil Structure, and Shortwave Albedo}

The effects of water content on normalized shortwave albedo are shown for soils of differing surface structure in Fig. 5 and 6 . The mean wet (water content $>0.22 \mathrm{~kg}$ $\left.\mathrm{kg}^{-1}\right)$ and dry $\left(<0.10 \mathrm{~kg} \mathrm{~kg}^{-1}\right)$ soil albedo for the various treatments are shown in Table 3 together with the corresponding surface roughness (LD index) and the percentage of aggregates $<18-\mathrm{mm}$ diam. In a dry condition, the soil color (Munsell standard colors) was greyish yellow brown (10YR 2/3) and, when wet, brown (10YR 5/ 3).

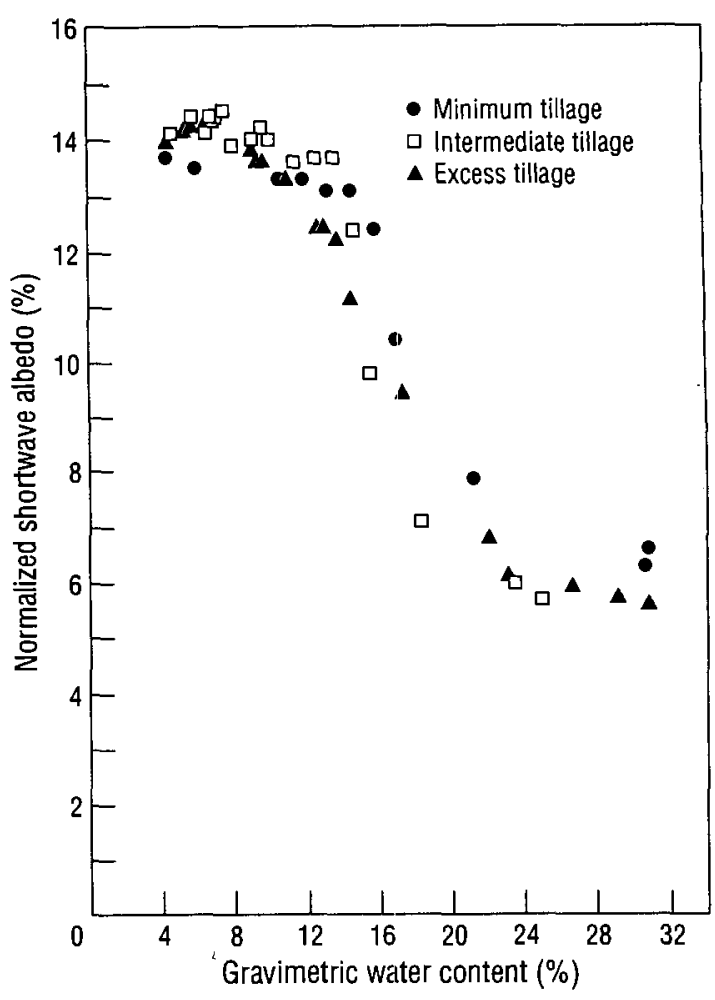

Fig. 6. Effect of soil water content on the normalized bare soil shortwave albedo (all tillage sequences conducted at pretillage soil water content of $0.18 \mathrm{~kg} \mathrm{~kg}^{-1}$ ).

Large changes in albedo with surface soil water content were observed. The characteristic shapes of the albedo vs. water content curves measured in this study concur with the observations of Idso et al. (1975), where the same depth of soil was sampled. Soil water content was determined at a depth of 0 to $20 \mathrm{~mm}$ as necessitated by the rough nature of the soil surface. Albedo is expected to be a function of the water content at the very surface of the soil. Water content changed markedly with depth and hence the use of a mean water content at this depth might dilute the albedo-water content relation. These results, then, are specific to the $0-$ to $20-\mathrm{mm}$ depth and do not show the relation between shortwave albedo and the water content at the very surface of the soil. However, the relation presented here is of practical value for field measurements.

Twomey et al. (1986) suggested that the primary reason for the albedo of wet soil to be lower than that of dry soil is that changing the medium around the particles from air to water decreases the relative refractive index and hence increases the "forwardness" of light scattering (i.e., scattering in the direction of the incident radiation). As a result, incident photons have to be scattered more times before they are turned around and emerge from the soil. Each scattering involves a finite probability of absorption, fewer photons survive the greater number of scattering events, and albedo is decreased.

The effects of differences in surface soil structure on albedo were small in comparison to the soil water content effects. Maximum variation in both dry and wet soil albedo (Table 3) across the full range of surface conditions was $2 \%$. The difference between the maximum and minumum albedo values observed across the full range 
Table 3. Effects of surface soil structure on shortwave albedo $\dagger$.

\begin{tabular}{lcccc}
\hline Treatment & $\begin{array}{c}\text { Dry soil } \\
\text { albedo }\end{array}$ & $\begin{array}{c}\text { Wet soil } \\
\text { albedo }\end{array}$ & $\begin{array}{c}\text { Surface } \\
\text { roughnes } \\
\text { (LD index) }\end{array}$ & $\begin{array}{c}\text { Aggregates } \\
<18-\mathrm{mm} \\
\text { diam. }\end{array}$ \\
\cline { 1 - 2 } $\begin{array}{l}\text { Minimum tillage } \\
\text { PTSW 0.32 kg kg-1 }\end{array}$ & 12.6 & 4.3 & 17.0 & $\%$ \\
$\begin{array}{l}\text { Minimum tillage } \\
\text { PTSW 0.18 kg kg-1 }\end{array}$ & 13.6 & 6.3 & 21.4 & 58.9 \\
$\begin{array}{l}\text { Intermediate tillage } \\
\text { PTSW 0.32 kg kg-1 }\end{array}$ & 13.3 & 5.7 & 16.7 & 61.8 \\
$\begin{array}{l}\text { Intermediate tillage } \\
\text { PTSW 0.18 kg kg-1 }\end{array}$ & 14.4 & 5.7 & 14.7 & 61.8 \\
$\begin{array}{l}\text { Excess tillage } \\
\text { PTSW 0.32 kg kg-1 }\end{array}$ & 14.6 & 5.8 & 10.2 & 78.0 \\
$\begin{array}{l}\text { Excess tillage } \\
\text { PTSW 0.18 kg kg-1 }\end{array}$ & 14.2 & 5.6 & 5.8 & 93.4 \\
\hline
\end{tabular}

$\uparrow$ Wet and dry soil albedo are albedo values measured at water contents $>0.22 \mathrm{~g} \mathrm{~g}^{-1}$ and $<0.10 \mathrm{~g} \mathrm{~g}^{-1}$, respectively. ‡ PTSW is pretillage soil water content.

of soil water content did not vary consistently with soil surface structure. Changing surface structure appears to have affected albedo by displacing the the whole albedowater content curve up or down; there was no clear indication of the rate of decrease in albedo with increasing water content being related to surface soil structure.

Differences in albedo between the tillage treatments at PTSW $0.32 \mathrm{~kg} \mathrm{~kg}^{-1}$ (Fig. 5) are larger than those at PTSW $0.18 \mathrm{~kg} \mathrm{~kg}^{-1}$ (Fig. 6), consistent with the larger variation in surface roughness and aggregate-size distribution between the curves in Fig. 5. The PTSW effects on albedo were largest with minimum tillage, reflecting the larger PTSW effects on aggregates $<18-\mathrm{mm}$ diam. With excess tillage, PTSW effects on albedo were negligible. Overall, the wide range of surface soil structural conditions produced by the tillage treatments had small effects on the shortwave albedo-soil water content relation. Hence on this soil, the range of tillage sequences and pretillage soil water contents used in commercial cereal cropping are not likely to cause significant changes in shortwave albedo.

The surface structure effect on albedo appears related more to the aggregate-size distribution than to the random roughness index. The correlation coefficient of dry soil albedo to random roughness was -0.59 , while the correlation with the percentage of aggregates $<18-\mathrm{mm}$ diam. was 0.81 . Random roughness does not relate well to aggregate-size distribution on the soil surfaces considered here. The aggregate-size distribution better relates to small-scale roughness, which appears to affect the albedo. A few large clods on the soil surface, which would have significant effects on the random roughness index, do not influence albedo to the same degree. The soil surfaces on which the albedo was measured represent an extreme range in a practical sense, although in terms of albedo they are all rough surfaces. In previous experimental work where large decreases in albedo have occurred from roughening a surface (e.g., Idso et al., 1975 ), the comparison has been made with artificially smooth surfaces created by rolling or puddling.

The soil surfaces considered here have low albedo values. This is probably due to the rough nature of the soil surfaces used, compared with those used for albedo observations by other workers. The other main reason is the high organic matter content of this soil $(6.2 \%)$. Total shortwave radiation receipt was very high in January 1988 when these measurements were made, with irradiance values in excess of $900 \mathrm{~W} \mathrm{~m}^{-2}$ being common.

\section{CONCLUSIONS}

Multiple-pass tillage operations significantly affect the soil water characteristic near saturation, with intensive tillage decreasing macroporosity mainly because of a reduction in the volume of large aeration pores. The slope of the water characteristic across the matric potential range -1.0 to $-1500 \mathrm{kPa}$ was not affected by widely contrasting tillage systems although the excess tillage sequence resulted in greater water contents at each matric potential within this range. Pretillage soil water content did not have significant effects on the water characteristic.

Tillage sequences significantly affect near-saturation hydraulic conductivity. More intensive tillage resulted in smaller hydraulic conductivity measured at $-0.4 \mathrm{kPa}$ matric potential. The relationship between hydraulic conductivity and water content was also affected by tillage sequences, with intermediate tillage resulting in the largest unsaturated conductivities across a wide range of water contents. However, there were inconsistencies between predicted unsaturated hydraulic conductivity and the pore-size distribution inferred from the soil water characteristic. While wide ranges in soil water content prior to tillage do affect the soil structure produced from tillage operations (Cresswell et al., 1991), these differences did not translate into significant changes in hydraulic properties of freshly tilled soil.

Comparison of results from this and earlier studies indicates that bare soil shortwave albedo variation with zenith angle is soil specific. In this study, there was a small decrease in albedo as zenith angle increased. Water content of the surface soil has a large effect on bare soil shortwave albedo, with a drier soil having a higher shortwave albedo. The different surface soil structures produced by the tillage treatments did not result in consistent differences in the shortwave albedo-soil water content relation. Soils with rough, cloddy surfaces generally had slightly decreased albedo although the differences in albedo across the range of surfaces produced in this study were small and not always consistent. The effects of surface roughness on albedo were generally small in comparison to the soil water content effects. Bare soil albedo was more strongly correlated to the small-scale roughness derived from aggregate-size distribution than to the larger scale random surface roughness index (LD index).

The range of tillage-induced soil structures produced in this soil are likely to affect evaporation from freshly tilled soil through differences in the supply of water to the evaporating sites rather than through differences in available energy supply. Tillage-induced changes in albedo were small and the initial energy-limited stage of evaporation will last only a short time, after which evaporation will be limited by the supply of water to evaporation sites. This supply is directly affected by soil hydraulic properties. In tillage management to optimize seedbed soil-water relations, the emphasis should therefore be on creating the desired seedbed hydraulic properties rather than on attempting to manipulate shortwave 
albedo. Pretillage soil water contents representative of normal field conditions do not appear useful to manipulate hydraulic properties and shortwave albedo in freshly tilled Templeton silt loam soil where commonly adopted tillage sequences are used. However, long-term effects of the tillage and PTSW treatments on soil structure may differ from the short-term results presented here.

Research is required to understand the temporal changes in surface soil hydraulic properties and surface soil structure following tillage. Differences in temporal change in these properties following different tillage treatments might prove to be of more significance than the differences between them immediately following tillage.

\section{ACKNOWLEDGMENTS}

This research was made possible by financial assistance from the New Zealand University Grants Committee, the National Water and Soil Conservation Authority, and the Department of Scientific and Industrial Research. The assistance of Mr. David Lees, Mr. Roger McLenaghen, and the staff of the Field Service Center, Lincoln University, is gratefully acknowledged.

\section{REFERENCES}

Allmaras, R.R., R.E. Burwell, W.E. Larson, and R.F. Holt. 1966 Total porosity and random roughness of the interrow zone as influenced by tillage. USDA-ARS Conserv. Res. Rep. no. 7. U.S. Gov. Print. Office, Washington, DC.

Ball, D.F. 1964. Loss-on-ignition as an estimate of organic matter and organic carbon in non-calcareous soils. J. Soil Sci. 15:84 92.

Burdine, N.T. 1953. Relative permeability calculations from poresize distribution data. Trans. Am. Inst. Min. Metall. Pet. Eng. 198:71-77.

Christiansen, J.E. 1942. Irrigation by sprinkling. Calif. Agric. Exp. Stn. Bull. no.670.

Clothier, B.E., and I. White. 1981. Measurement of sorptivity and soil water diffusivity in the field. Soil Sci. Soc. Am. J. 45:241-245.

Coulson, K.L., and D.W. Reynolds. 1971. The spectral reflectance of natural surfaces. J. Appl. Meteorol. 10:1285-1295.

Cresswell, H.P. 1990. Surface soil structure, the soil water balance and the effects of tillage. Ph.D. diss. Lincoln Univ., Canterbury, New Zealand.

Cresswell, H.P., D.J. Painter, and K.C. Cameron. 1991. Tillage and water content effects on surface soil physical properties. Soil Tillage Res. 21:67-83.

Cresswell, H.P., D.E. Smiles, and J. Williams. 1992. Soil structure, soil hydraulic properties and the soil water balance. Aust. J. Soil Res. 30:265-283.

Currence, H.D., and W.G. Lovely. 1970. The analysis of soil surface roughness. Trans. ASAE 13:710-714.

De Leenheer, L. 1977. Soil fertility study in maximizing crop yield on mechanical farms in Belgium: general and agricultural conclusions of a 15 year study (1961-1975). p.133-144. In Proc. Int. Sem. Soil Environ. Fert. Manage. Int. Agric., Kyoto. 20 Aug. 1977. Soc. Sci. Soil Manure, Tokyo.
GENSTAT 5 Committee. 1987. GENSTAT 5 reference manual. Clarendon Press, Oxford, England.

Gradwell, M.W. 1972. Methods for physical analysis of soils N.Z. Soil Bur. Sci. Rep. 10C. DSIR, Wellington, New Zealand.

Idso, S.B., R.D. Jackson, R.J. Reginato, B.A. Kimball, and F.S. Nakayama. 1975. The dependence of bare soil albedo on soil water content. J. Appl. Meteoroll. 14:109-113.

Incropera, F.P., and D.P. de Witt. 1985. Fundamentals of heat and mass transfer. 2nd ed. John Wiley \& Sons, New York.

Irons, J.R., G.S. Campbell, J.M. Norman, D.W. Graham, and W.M. Kovalick. 1992. Prediction and measurement of soil bidirectional reflectance. IEEE Trans. Geosci. Remote Sens. 30:249-260.

Jackson, R.D., P.M. Teillet, P.N. Slater, G. Fedosejevs, M.F. Jasinski, J.J. Aase, and M.S. Moran. 1990. Bidirectional measurements of surface reflectance for view angle corrections of oblique imagery. Remote Sens. Environ. 32:189-202.

Kear, D.S., H.S. Gibbs, and R.B. Miller. 1967. Soils of the downs and plains of Canterbury and North Otago, New Zealand. Soil Bur. Bull. no. 14. DSIR, Wellington, New Zealand.

Klute, A. 1982. Tillage effects on hydraulic properties of soil: A review. p. 29-43. In P.W. Unger et al. (ed.) Predicting tillage effects on soil physical properties and processes. ASA Spec. Publ. no. 44. ASA and SSSA, Madison, WI.

Linden, D.R., and D.M. Van Doren, Jr. 1986. Parameters for characterizing tillage-induced soil surface roughness. Soil Sci. Soc. Am. J. 50:1560-1565.

Lyles, L., J.D. Dickerson, and L.A. Disrud. 1970. Modified rotary sieve for improved accuracy. Soil Sci. 109:207-210.

Marshall, T.J., and J.W. Holmes. 1988. Soil physics. 2nd ed. Cambridge Univ. Press, Cambridge, England.

Monteith, J.L., and M.H. Unsworth. 1990. Principles of environmental physics. 2nd ed. Edward Arnold, London.

Rawls, W.J., and D.L. Brakensiek. 1989. Estimation of soil water retention and hydraulic properties. p. 275-300. In H.J. MorelSeytoux (ed.) Unsaturated flow in hydrologic modelling Theory and practice. Kluwer Acad. Publ., Dordrecht, the Netherlands.

Reifsnyder, W.E. 1967. Radiation geometry in the measurement and interpretation of the radiation balance. Agric. Meteorol. $4: 255-265$.

Soil Survey Staff. 1990. Keys to soil taxonomy. 4th ed. Soil Manage. Support Serv. Tech. Monogr. no. 19. Virg. Polytechnic Inst. and State Univ, , Blacksburg.

Steel, R.G.D., and J.H. Torrie (ed.). 1981. Principles and procedures of statistics - A biometrical approach. McGraw-Hill Int. Book Co., Tokyo.

Thomas, R.F. 1973. Test methods for soil engineering. N.Z. Soil Bur. Sci. Rep. 10E. DSIR, Wellington, New Zealand.

Twomey, S.A., C.F. Bohren, and J.L. Mergenthaler. 1986. Reflectance and albedo differences between wet and dry surfaces. Appl. Optics 25:431-437.

Van Bavel, C.H.M., and D. Hillel. 1976. Calculating potential and actual evaporation from a bare soil surface by simulation of concurrent flow of water and heat. Agric. Meteorol. 17:453476.

van Genuchten, M.Th. 1978. Calculating the unsaturated hydraulic conductivity with a new closed-form analytical model. Res. Rep. 78-WR-08. Dep. of Civ. Eng., Princeton Univ., Princeton, NJ.

van Genuchten, M.Th. 1980. A closed form equation for predicting the hydraulic conductivity of unsaturated soils. Soil Sci. Soc. Am. J. 44:892-898. 